\title{
UPTAKE OF HORSERADISH PEROXIDASE BY THE TESTIS AND EPIDIDYMIS OF MICE
}

\section{ELECTRON MIGROSCOPIG STUDY OF THE TESTIS}

\author{
J. A. ARAGON AND LIVIA LUSTIG \\ Centro de Investigaciones sobre Reproducción, \\ Facultad de Medicina, Buenos Aires, Argentina
}

(Received 26th Fanuary 1972)

\begin{abstract}
Summary. Thirty-five male mice were intravenously injected with horseradish peroxidase and killed at regular intervals between $1 \mathrm{~min}$ and $24 \mathrm{hr}$. Small pieces of testis were processed for electron microscopy and peroxidase was demonstrated in the capillary lumen, macrophages, Leydig cells and tubular wall, as early as $1 \mathrm{~min}$ after its injection. Inside the tubule, the reaction product was present in the intercellular cleft between Sertoli cells, spermatogonia and preleptotene spermatocytes. Peroxidase was present in dense bodies in the basal portion of the Sertoli cell and as a diffuse pattern in the apical cytoplasm surrounding spermatids, confirming the important rôle played by this cell in the transport of macromolecules. The fact that the reaction product was only present in certain areas of the seminiferous tubules suggests the existence of a relative blood-testis barrier to this tracer.
\end{abstract}

\section{INTRODUCTION}

The permeability of the seminiferous tubule has been studied for many years, using dyes, isotopically labelled compounds and other substances easily identifiable at the microscopic level. Protein tracers were used in more recent studies. Everett \& Simmons (1958), using intravenously injected labelled serum albumin, found it in the extravascular compartment of the testis. Mancini, Vilar, Alvarez \& Seiguer (1965) demonstrated the passage of fluoresceinlabelled serum proteins through the extravascular spaces and the seminiferous tubules of the rat testis. Reddy \& Svoboda (1967) reported the uptake of horseradish peroxidase (HRP) by the cells of the germinal epithelium but principally by the Sertoli cell of the rat testis. Recently, Fawcett, Leak \& Heidger (1970) using several tracers, such as carbon, thorium, ferritin and HRP injected interstitially into the guinea-pig testis, found that the barrier was localized in the myoid-cell layer of the peritubular space or in the specialized junctions between adjacent Sertoli cells present in the basal area of the seminiferous tubules, depending on the size of the particles.

As a result of all these studies that demonstrate a selective permeability of the seminiferous tubules to different substances, the existence of a blood-testis barrier has been postulated. 
An earlier report (Aragon, Lustig \& Mancini, 1972) concerned the uptake of intravenously injected HRP by certain areas of the peritubular wall and by the cells of the seminiferous tubules of the mouse testis. In the present report, we confirm these results at the ultrastructural level.

\section{MATERIALS AND METHODS}

As already described, HRP (Sigma, type II), in a dose of $8 \mathrm{mg} /$ animal dissolved in $0.3 \mathrm{ml}$ saline solution, was injected intravenously into the tail of thirty-five male mice (Rockland) varying in weight from 25 to $30 \mathrm{~g}$.

Animals were killed 1, 5, 15, 30, 60, 90 and $120 \mathrm{~min}$ and 3, 6, 9, 12, 18 and 24 $\mathrm{hr}$ following injection. Small pieces of the testis were fixed for $4 \mathrm{hr}$ in cold $5 \%$ glutaraldehyde in $0.1 \mathrm{~m}$-phosphate buffer, $\mathrm{pH} 7 \cdot 6$, or in $4 \%$ formaldehyde and $5 \%$ glutaraldehyde in $0.1 \mathrm{~m}$-cacodylate buffer, $\mathrm{pH} 7.2$. Tissues were washed overnight in $0.1 \mathrm{M}$-phosphate buffer containing $5 \%$ sucrose or 0.1 M-cacodylate buffer, $\mathrm{pH} 7 \cdot 2$, respectively, according to the method described by Graham \& Karnovsky (1966).

In some animals, fixation by perfusion was performed as previously described (Aragon et al., 1972) and the tissues were post-fixed for $4 \mathrm{hr}$ in $5 \%$ glutaraldehyde.

Frozen sections of 30 to $40 \mu \mathrm{m}$ obtained in a cryostat or small fragments of isolated seminiferous tubules were incubated for $1 \mathrm{hr}$ at $4^{\circ} \mathrm{C}$ with a saturated solution of 3-3' diaminobenzidine (free base) in $0.05 \mathrm{M}$-tris- $\mathrm{HCl}$ buffer, $\mathrm{pH}$ 7.6. The scctions were then incubated for $30 \mathrm{~min}$ with the complete substrate (3-3' diaminobenzidine) and 0.001\% hydrogen peroxide at room temperature, according to the method of Nakane \& Pierce (1967) and subsequently embedded in Epon-Araldite or Maraglass.

Thick sections $(1 \mu \mathrm{m})$ were observed under the light microscope and thin sections were observed unstained in a Zeiss EM-9A, or counterstained with uranyl acetate.

The following controls were used: (1) animals injected with saline solution and tested for peroxidase activity; (2) uninjected animals to test for the presence of endogenous peroxidase; (3) animals injected with peroxidase but not tested for peroxidase activity.

\section{RESULTS}

Results have shown different localizations of HRP in the testis depending on the time following injection.

During the first $15 \mathrm{~min}, \mathrm{HRP}$ was simultaneously present in the following structures: the lumen of the blood vessels, the narrow intercellular spaces between adjacent endothelial cells, a few micropinocytosis vesicles in the cytoplasm of these cells, and the lumen of the lymphatic vessels (Pl. 1, Fig. 1). Peroxidase was present in the intercellular areas among Leydig cells and in the cytoplasm of these cells, as early as $1 \mathrm{~min}$ after injection and appeared as dense bodies or in a diffuse pattern. The dense bodies presented different sizes and a non-homogeneous density which distinguished them from the lipid droplets 
present in normal mice (Pl. 1, Fig. 1). Macrophages were also loaded with HRP within the first few minutes following injection. The enzymatic activity was present in these cells for at least $24 \mathrm{hr}$. The reaction product was observed in the wall (internal and external lamellae of the lamina propia) of the seminiferous tubules as early as $1 \mathrm{~min}$ after injection, with a maximum intensity at 15 min which decreased thereafter. This localization was only observed in certain areas of the tubular wall. Horseradish peroxidase was also observed in the intercellular spaces between adjacent interlamellar cells and in micropinocytosis vesicles in the cytoplasm of these cells (Pl. 1, Fig. 2). In some areas rich in reaction product, the internal lamella presented numerous indentations of multiple shapes and sizes, towards the basal epithelium (Pl. 1, Figs 3 and 4). Peroxidase was observed sometimes through the intercellular spaces between Sertoli cells and spermatogonia, showing a direct communication between the internal lamella and the intercellular gap (Pl. 1, Fig. 2). In certain areas of the tubule, HRP was found in the intercellular spaces surrounding spermatogonia and preleptotene spermatocytes (Pl. 2, Figs 5 and 6). In a few cases, HRP was observed around leptotene spermatocytes.

Even if the reaction product observed in the wall or inside the seminiferous tubules was not uniformly distributed among the sections, the testis of all animals studied in this period presented 'positive' areas.

Dense bodies and micropinocytosis vesicles with HRP were observed in the basal portion of the Sertoli-cell cytoplasm (PI. 1, Figs 3 and 4) and in a diffuse pattern in the apical cytoplasm surrounding spermatids and spermatozoa (Pl. 2, Figs 9 and 10).

Within $30 \mathrm{~min}$ of the injection, the reaction product was no longer present in the intercellular gap between Sertoli and germinal cells. The dense bodies observed in the basal cytoplasm of the Sertoli cells were mainly localized in the cell body (Pl. 2, Figs 7 and 8).

After $1 \mathrm{hr}$ and during the subsequent $24 \mathrm{hr}$, the reaction product was only present in the dense bodies of the Sertoli-cell body and the interstitial cells, decreasing in number progressively with time.

In control animals uninjected or injected with saline solution alone, whose testes had been processed with the substrate for peroxidase, a low enzyme activity was only seen in some of the dense bodies usually present in certain Sertoli cells and this corresponded to endogenous peroxidase. In other control animals which were injected with HRP but whose testes were not processed with the substrate, no positive reaction could be demonstrated.

\section{DISCUSSION}

Horseradish peroxidase was introduced as a tracer by Straus (1957) and used in ultrastructural studies by Karnovsky (1965) and Graham \& Karnovsky (1966). The advantages of this enzyme are its relatively low molecular weight $(40,000)$ which facilitates studies of permeability, the fact that it is possibile to detect very low concentrations of the enzyme and that it can be used in electron microscopy, due to the formation of an electron-opaque reaction product. 
As technical artifacts to be taken into account, it is necessary to consider: (a) factors that could increase the permeability, such as the volume of the injection, the release of histamine and serotonin following injection, the toxicity of the enzyme, and the preservation of the processed tissue; and (b) the non-specific adsorption of HRP.

We think that the volume injected in the present experiment $(0.3 \mathrm{ml} /$ mouse $)$ was not an important factor in increased permeability. This is based on the results obtained by Karnovsky (1967) and Schneeberger \& Karnovsky (1971) who, measuring the width of intercellular junctions, demonstrated that an intravenous injection of HRP diluted in a larger volume $(0.5 \mathrm{ml} / \mathrm{mouse})$ does not cause anatomical or ultrastructural disruption of endothelial junctions. Moreover, Karnovsky (1967) ruled out the possibility of a significant release of histamine and serotinin in mice after the intravenous injection of HRP, a phenomenon that occurs in rats and guinea-pigs. We cannot eliminate the possibility of a toxic effect of the enzyme because no metabolic studies were carried out, but the ultrastructure of the germinal epithelium of the injected animals showed no morphological differences when compared with that of the control animals and the amounts of HRP used were within the limits of non-toxicity reported in kidney by Straus (1971). Fawcett et al. (1970) did not report a toxic effect in the testes of guinea-pigs injected locally with a high dose of HRP ( $30 \mathrm{mg} / \mathrm{animal}$ ).

Preservation of the tissue was not optimal because of the use of frozen sections, but the same localization of the reaction product was observed in some of the small fragments of isolated tubules processed in the same way as the frozen sections. Even though this material was better preserved, an exhaustive study of it was not carried out because, as in all thick preparations, a nonuniform degree of reaction was present from the peripheral to the innermost portions. To decrease the non-specific adsorption of peroxidase, hypertonic sucrose was added to the washing fluids used after fixation and, in order to avoid diffusion artifacts, some animals were perfused with the fixative (Straus, 1967a). Similar results were obtained in perfused and non-perfused animals.

The appearance of HRP in the lumen of the capillaries, in the intercellular spaces between adjacent endothelial cells and in a few micropinocytosis vesicles within $1 \mathrm{~min}$ of its injection, is in accordance with the observations previously reported by Karnovsky (1967) in cardiac and skeletal muscle capillaries.

\section{EXPLANATION OF PLATE I}

All sections of mouse testis were treated for peroxidase and unstained.

FIg. 1. Interstitial tissue $5 \mathrm{~min}$ after peroxidase injection. The reaction product was found in the capillary lumen (C), apparently in micropinocytosis vesicles (arrow) of the endothelial cell (E) and in the dense bodies in the Leydig cell (L). $\times 17,000$.

Fig. 2. Basal portion of a seminiferous tubule $15 \mathrm{~min}$ after peroxidase injection. The reaction product was found in the internal and external lamellae, micropinocytosis vesicles in the myoid cells (M, arrow) and spermatogonia (G). Peroxidase reaction was also found in the intercellular gap between spermatogonia and Sertoli cell $(S) . \times 17,000$.

Figs 3 and 4. Same conditions as in Fig. 2. The reaction product was found in the internal and external lamellae, in the intercellular gap between two myoid cells (indicated by triangles) and in apparent micropinocytosis vesicles in the Sertoli cells $(\mathbf{S}$, arrow). Some peroxidase was also found in the basal portion of the intercellular gap between two Sertoli cells (S), but not deeper. $\times 17,000$ and $\times 45,600$, respectively. 


\section{PLATE 1}
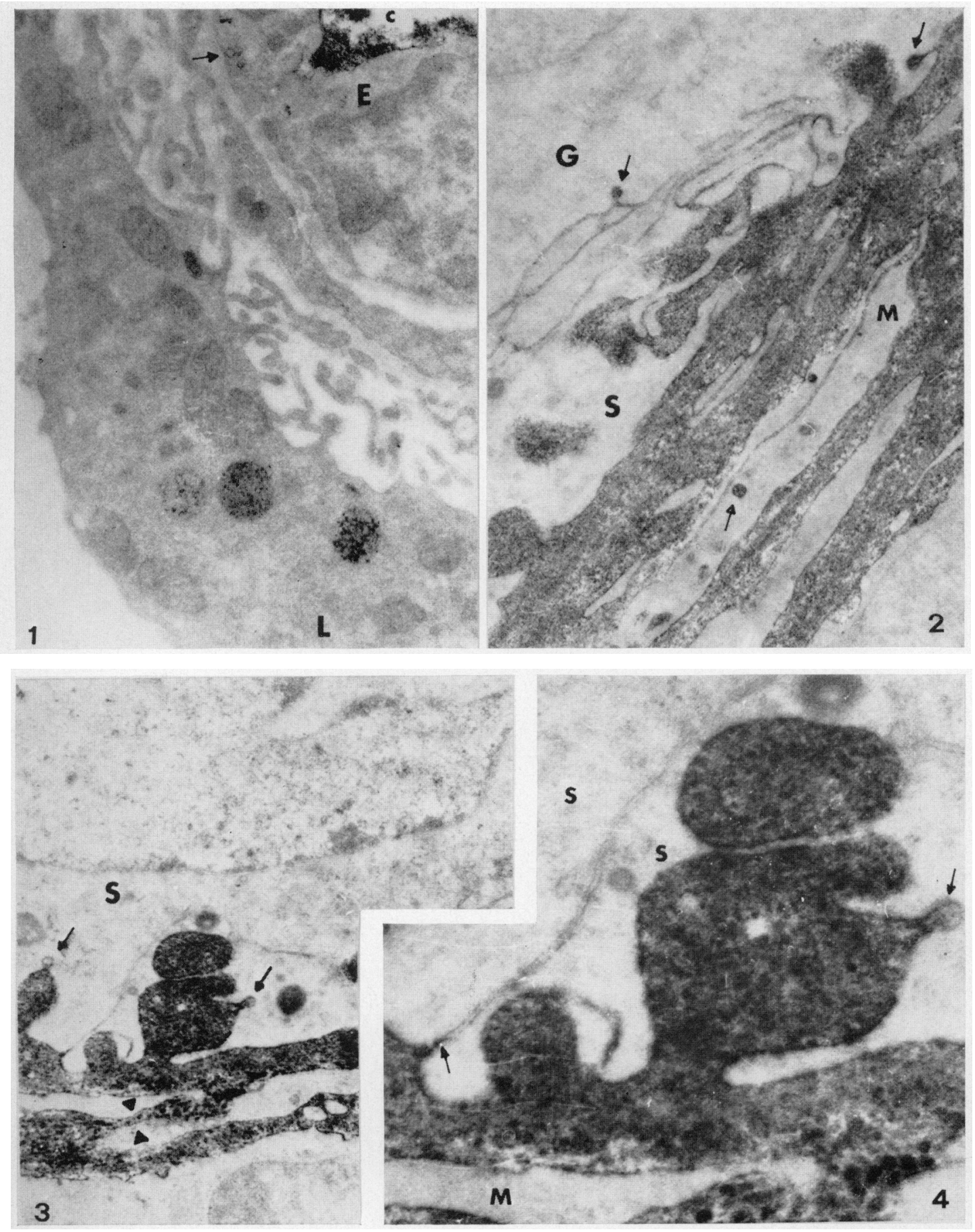

(Facing p. 192) 


\section{PLATE 2}
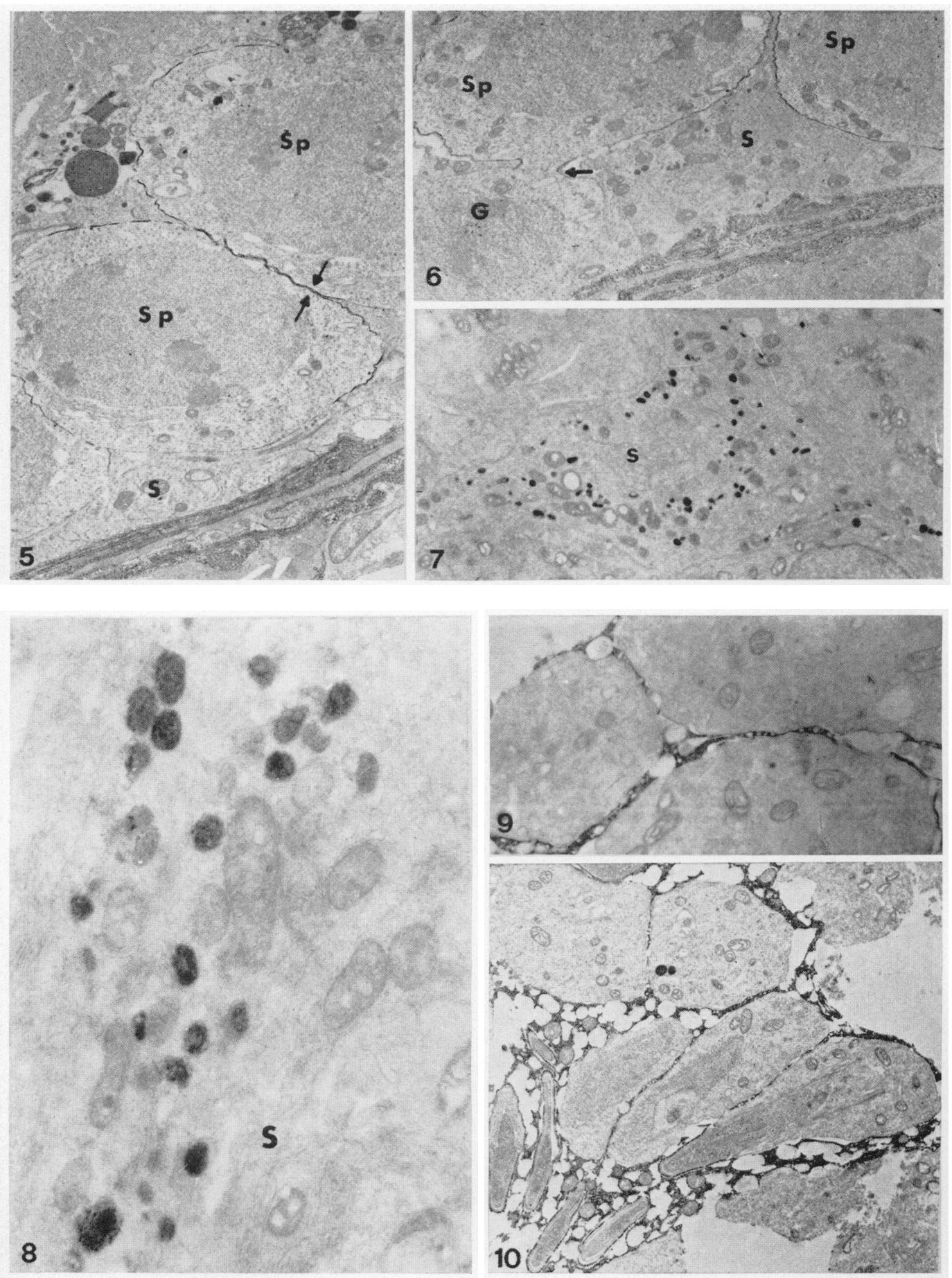

(Facing p. 193) 
The lymphatic vessels, which are regarded as a route for the drainage of substances injected intravenously, were loaded with HRP during the first few minutes following its injection, and during its passage to the seminiferous tubules.

Our results concerning the localization of the HRP in the tubular wall confirm those reported by Dym \& Fawcett (1970), who observed that when rats were perfused with lanthanum-glutaraldehyde, the tracer penetrated through the open junctions of the myoid cells (interlamellar cells) in some areas of the tubules. The use of HRP by the intravenous route, allowed us to confirm this phenomenon in vivo and also to observe the passage of the enzyme from the external to the interlamellar cells.

Although the passage of HRP through the tubular wall and the intercellular spaces of the germinal epithelium was not uniform, the testes of all animals studied presented peroxidase-positive areas, confirming the observations at the light-microscopic level (Aragon et al., 1972), where an approximate $40 \%$ of the tubules per section showed the reaction product. Previous works related to the permeability of the seminiferous tubules (Vilar \& Mancini, 1970; Fawcett et al., 1970; Seiguer \& Mancini, 1971) also demonstrated a non-uniform passage of the different tracers used.

Once the HRP enters the seminiferous tubule, it follows two different routes: one, through the intercellular gap between Sertoli cells and germinal cells; the other, through the Sertoli-cell cytoplasm.

Our results may also be compared with the findings of Fawcett et al. (1970) who injected HRP into the interstitial tissue of the guinea-pig testis and noted the reaction product in the intercellular cleft between the spermatogonia and the Sertoli cells and not in the intercellular gap between two Sertoli cells because of the presence of the specialized junctions. Our findings differ, however, in that we observed the HRP at a deeper level in the germinal epithelium (primary spermatocytes). The different results obtained by Fawcett et al. (1970) in guinea-pigs could be due to the difference in the species involved and to the different route of injection used.

Dym \& Fawcett (1970) suggested that the seminiferous tubules are formed by

\section{EXPLANATION OF PLATE 2}

All sections of mouse testis were treated for peroxidase and unstained.

Frg. 5. Basal portion of a seminiferous tubule $15 \mathrm{~min}$ after peroxidase injection. The reaction product was found in the tubular wall and in the intercellular space (arrows) between preleptotene spermatocytes $(\mathrm{Sp})$ and Sertoli cell $(\mathrm{S}) \times \times 5700$.

Fig. 6. Same conditions as in Fig. 5. The reaction product was found in the intercellular gap (arrow) between Sertoli cell (S) and spermatogonia (G) and Sertoli cell and preleptotene spermatocytes $(\mathrm{Sp}) . \times 5700$.

Frg. 7. Seminiferous tubule $30 \mathrm{~min}$ after peroxidase injection. The reaction product was found in numerous dense bodies in the body of the Sertoli cell $(S) . \times 4200$.

Frg. 8. Same conditions as in Fig. 7. $\times 17,000$.

Fig. 9. Apical portion of Sertoli cell $15 \mathrm{~min}$ after injection of peroxidase. The reaction product was found in the Sertoli apical cytoplasm surrounding spermatids. $\times 8400$.

FIG. 10. Same as in Fig. 9. The reaction product was found in the vacuolated apical cytoplasm of the Sertoli cell around spermatids in different stages of spermiogenesis. $\times 4200$. 
two compartments: (1) a basal compartment between the Sertoli-cell junctions and the basal lamina, containing the spermatogonial population and preleptotene spermatocytes; and (2) an adluminal compartment above the Sertolicell junctions, containing the other germinal cells. Our results in certain areas, however, show passage of the tracer through the intercellular clefts of all the cells of the basal compartment (spermatogonia and preleptotene spermatocytes) and, in a few cases, through the intercellular spaces between the spermatocytes and Sertoli cells and the adluminal compartment.

Flickinger \& Fawcett (1967) and Dym \& Fawcett (1970) suggested that the specialized junctions of adjoining Sertoli cells play an important rôle in the synchronization of the spermatogenic wave, permitting the passage of the germinal cells towards the lumen. This phenomenon could explain our observations concerning the presence of HRP in the adluminal compartment.

The sequence observed concerning the uptake of HRP by the Sertoli cells indicates that the HRP present in the intercellular spaces was taken up by the Sertoli cell from where it was transported to the lumen or metabolized. Straus (1967b) suggested that the passage of HRP through the spaces between endothelial cells can also be combined with a short intracellular transport by micropinocytosis vesicles bypassing the 'tight junctions'. This phenomenon was observed by the author in the distal tubular cells of the kidney and by Kaye \& Pappas (1962), who used colloidal particles as tracers to study the uptake by the endothelial cells of the cornea.

The rôle of the Sertoli cell as a transporting cell system connecting the extravascular space with the germinal epithelium and the tubular lumen has been previously suggested by Vilar, Perez del Cerro \& Mancini (1962) in a morphological study, by Mancini et al. (1965) using labelled serum proteins in rat testis, by Reddy \& Svoboda (1967) using HRP intravenously injected in rats and by Vilar \& Mancini (1970) in in-vivo and in-vitro studies using ferritinlabelled albumin and ferrocyanide as tracers. Seiguer \& Mancini (1971) arrived at the same conclusions following studies in which they injected ferrocyanide in vivo.

Finally, we would emphasize that: (1) the passage of HRP only takes place in some of the seminiferous tubules and in a given tubule, the diffusion is restricted to certain areas; (2) when the HRP enters the seminiferous tubule, it is usually observed in the intercellular spaces between the cells of the basal compartment (spermatogonia and preleptotene spermatocytes), but in certain areas a small amount of it can pass through the specialized junctions appearing in the intercellular gaps deeper in the epithelium; (3) the Sertoli cell plays an important rôle in the transport of HRP from the tubular wall to the lumen.

The existence of a selective blood-testis barrier has been postulated by several authors. Our findings using HRP as a tracer suggest that the so-called bloodtestis barrier is a partial or relative one, as it is only present in certain areas of the tubule.

\section{ACKNOWLEDGMENTS}

This work has been supported by funds from the Ford Foundation and Population Council N.M.69.16. One of the authors (J.A.A.) is a Fellow of the Curso 
Latino-Americano de Biologia de la Reproducción, from the Universidad del Valle, Cali, Colombia.

\section{REFERENCES}

ARAgon, J. A., Lustig, L. \& MANcini, R. E. (1972) Uptake of horseradish peroxidase by the testis and epididymis of mice. I. Light-microscopic study. F. Reprod. Fert. 28, 299.

Dym, M. \& FawcetT, D. W. (1970) The blood-testis barrier in the rat and the physiological compartmentation of the seminiferous epithelium. Biol. Reprod. 3, 308.

Everett, N. B. \& Simmons, B. (1958) Measurement and radioautographic localization of albumin in rat tissue after intravenous administration. Circulation Res. 6, 307.

Fawcett, D. W., Leak, L. V. \& Hemger, P. M., JR (1970) Electron microscopic observations on the structural components of the blood-testis barrier. 7. Reprod. Fert. Suppl. 10, 105.

Flickinger, C. \& FawcETt, D. W. (1967) The junctional specializations of Sertoli cell in the seminiferous epithelium. Anat. Rec. 158, 207.

Graham, R. G. \& Karnovsky, M. J. (1966) The early stages of injected horseradish peroxidase in the proximal tubules of mouse kidney: ultrastructural cytochemistry by a new technique. $\mathcal{F}$. Histochem. Cytochem. 14, 291.

Karnovsky, M. J. (1965) Vesicular transport of exogenous peroxidase across capillary endothelium into the T system of muscle. F. Cell Biol. 27, 49A.

KARNovsky, M. J. (1967) The ultrastructural basis of capillary permeability studied with peroxidase as a tracer. 7 . Cell Biol. 35, 213.

KAyE, G. I. \& Pappas, G. D. (1962) Studies on the cornea. I. The fine structure of the rabbit cornea and the uptake and transport of colloidal particles by the cornea in vivo. F. Cell Biol. 12, 457.

Mancini, R. E., Vilar, O., Alvarez, B. \& Seiguer, A. C. (1965) Extravascular and intratubular diffusion of labeled serum proteins in the rat testis. F. Histochem. Cytochem. 13, 376.

Nakane, P. K. \& Pierce, G. B. (1967) Enzyme-labeled antibodies for the light and electron microscopic localization of tissue antigens. J. Cell Biol. 33, 307.

Reddy, J. K. \& Svoboda, D. J. (1967) Peroxidase transport by Sertoli cells of the rat testis. F. Cell Biol. 35,184 A.

Schneeberger, E. E. \& Karnovsky, M. J. (1971) The influence of intravascular fluid volume on the permeability of newborns and adult mouse lungs to ultrastructural protein tracers. 7 . Cell Biol. 49, 319.

Seiguer, A. C. \& Mancins, R. E. (1971) The permeability of the 'blood-testis' barrier to ferrocyanide. 7. Reprod. Fert. 27, 269.

Straus, W. (1957) Segregation of an intravenously injected protein by 'droplets' of the cells of rat kidney. F. biophys. biochem. Cytol. 3, 1037.

Straus, W. (1967a) Methods for the study of small phagosomes and their relationship to lysosomes with horseradish peroxidase as a 'marker protein'. $\mathcal{J}$. Histochem. Cytochem. 15, 375.

Straus, W. (1967b) Changes in the intracellular location of small phagosomes (micropinocytic vesicles) in kidney and liver cells in relation to time after injection and dose of horseradish peroxidase. 7. Histochem. Cytochem. 15, 381 .

Straus, W. (1971) Gomparative analysis of the concentration of injected horseradish peroxidase in cytoplasmic granules of the kidney cortex, in blood, urine and liver. F. Cell Biol. 48, 620.

Vilar, O. \& MANcini, R. E. (1970) In vivo and in vitro intratubular diffusion and uptake of different substances by rat Sertoli cells. Acta Europ. Fert. 2, 193.

Vilar, O., Perez del Cerro, M. E. \& Mancini, R. E. (1962) The Sertoli cell as a 'bridge cell' between the basal membrane and the germinal cells. Expl Cell Res. 27, 158. 